\title{
México 2013. Los vuelcos de la historia. Del nacionalismo revolucionario al neoliberalismo*
}

\author{
Doralicia Carmona Dávila \\ Universidad de Guanajuato
}

Resumen

La crisis energética, la dictadura de Pinochet, los secuestros y asesinatos de empresarios en los setenta y, a partir de 1982, la nacionalización de la banca y la creciente petrolización del país, crearon el escenario para que los grandes empresarios lucharan por sustituir los principios de la Revolución Mexicana, nunca del agrado del capitalismo internacional, por el neoliberalismo. La caída de la URSS, la pérdida de legitimidad del priísmo y la parálisis económica ofrecieron a los grandes empresarios la oportunidad de ganar poder político y dar a la historia del siglo XX mexicano un vuelco, que ha sido terso por el control que las élites dominantes ejercen, mediante una sofisticada propaganda televisiva, sobre una sociedad mayoritariamente indiferente, desigual, pobre e ignorante. No obstante, aunque crezca la economía, sin democratización, el vuelco aumentará la desigualdad, la violencia, el crimen y el autoritarismo gubernamental.

* Este artículo se leyó originalmente en la clausura del III Congreso de Filosofía de la Historia de la Universidad de Guanajuato el 26 de noviembre de 2013. Aquí se reproduce con algunas modificaciones. 
Palabras clave: Nacionalismo, neoliberalismo, pérdida de legitimidad, desigualdad.

\section{Abstract}

The energy crisis, the Pinochet dictatorship, the kidnappings and assassinations of businessmen in the seventies and, from 1982, the nationalization of the banks and increased "petrolization" of the country, set the stage for the big business men fight to replace the principles of Mexican Revolution, never of the liking of the international capitalism, by neoliberalism. The fall of the USSR, the loss of legitimacy of the PRI and economic paralysis offered the opportunity to the richest businessmen to gain political power and give the history of the twentieth century Mexican a overturn, that's has been smooth because of the control that the dominant elites exert, through a sophisticated TV propaganda, on a largely indifferent, unequal, poor and ignorant society. Nevertheless, even if democracy grows, without democratization, the overturn will increase inequality, violence, crime and government authoritarianism.

Keywords: Nationalism, Neoliberalism, Loss of legitimacy, Inequality.

Ceptiembre de 1973: mes y año que señalan el rumbo de la his$\checkmark$ toria hacia el futuro neoliberalismo. Un cambio que abarcará todos los aspectos de la vida humana y la manera de ver el mundo, la vida y aun la Historia. Un cambio que prometerá progreso para todos, pero que provocará desempleo y pobreza para los pueblos y acumulación de poder y de riqueza para sus élites gobernantes. Un cambio que acelerará el deterioro y los desastres ecológicos. Un cambio que seguimos viviendo con mayor rapidez, pero hoy con violencia y sangre. Veamos cómo sucedió ese cambio.

Día 11 de septiembre, Chile: un golpe militar, auspiciado por los Estados Unidos, pone fin al gobierno democrático de Salvador 
Allende. En los siguientes quince años que durará la dictadura, se pondrán en práctica las ideas del neoliberalismo que hoy mueven al mundo capitalista.

Día 14 de septiembre, México: en un acto de solidaridad con el derrocado gobierno de Allende, Jesús Reyes Heroles (Carmona, 2014: internet), presidente del Comité Ejecutivo del PRI, analiza el significado del cuartelazo y los rasgos que adoptará el nuevo régimen que implantará en Chile la nueva dictadura militar, en los términos que leo a continuación:

Se trata de un nuevo fascismo [...] Si el viejo fascismo [...] quería dominar pueblos, explotar tierras y hombres con la fuerza y la hegemonía militar, el nuevo fascismo colonial encuentra su apoyo en el hecho de que los grandes monopolios internacionales exploten despiadadamente los recursos naturales de su país; quiere evitar las tensiones y conflictos imponiéndose con mano férrea a las contradicciones económicas; busca la alianza entre los monopolios internos y los externos, o mejor dicho, la subordinación de los primeros a los segundos, y facilita, acabando con la libertad sindical, con los derechos de los trabajadores, la mayor explotación de la mano de obra por los monopolios internos y externos.

En lugar de reivindicar los recursos naturales, los entrega al exterior, pretendiendo de esta manera resolver irresolubles contradicciones domésticas. Vender barato materias primas y alquilar a bajo precio mano de obra para que unos cuantos en el interior acaparen los beneficios de lo que la naturaleza ha dado y de lo que el hombre genera con su trabajo. Concentrar la tierra en antieconómicos latifundios y explotar al peón. Acaparar las grandes utilidades en unos cuantos nacionales subalternos de unos cuantos que dirigen las grandes empresas transnacionales. Reducir los salarios reales y, así, no sólo imponer la injusticia, sino cerrar cualquier posibilidad de contar con un mercado que sustente una industria autónoma. Contrarrestar la ineficacia económica con la inicua e irracional explotación de los recursos naturales y la más inicua y 
más irracional explotación de los recursos humanos. Centralizar el poder y arrogarse la minoría la facultad de pensar por todos.

Adentro se forma una pirámide, en cuya cúspide unos cuantos dominan, detentando el capital financiero. El Estado se queda con los malos negocios, necesarios para que los escasos poderosos obtengan utilidades; se construye la infraestructura que permita las grandes utilidades. Lo que se recoge de los más se les transfiere a los menos; las pérdidas de éstos se hacen públicas y se hacen privadas las utilidades nacionales. La ineficiencia de unos cuantos es compensada por el trabajo sin límite, más allá de la fatiga, de los más. Se instaura un paraíso para las empresas transnacionales, superpotencias económicas sin nacionalidad, que se sirven de los gobiernos, estados y patrias. En este ajedrez internacional, el fascismo colonial aspira a forjar numerosos peones (Carmona, 2014: internet).

Reyes Heroles, abogado, político e historiador, comprendió de inmediato que lo que aún no se conocía comúnmente como neoliberalismo era una tendencia poderosa y creciente del capitalismo internacional que amenazaba la ideología y la obra de los gobiernos de la Revolución Mexicana. Su voz es la voz de alerta del historiador que identifica algo que puede cambiar el mundo.

Día 15 de septiembre, Países Árabes: la Organización de Países Exportadores de Petróleo (OPEP) declara un frente de negociación para presionar al alza los precios y finalizar el apoyo a Israel. El 6 de octubre siguiente, Egipto y Siria atacan a Israel. Al ser derrotados, los árabes utilizan como arma el petróleo y decretan el embargo contra los países que apoyaron a los judíos. Los precios del crudo se disparan. La corriente neoliberal, aletargada desde la época de Roosevelt, endurece sus posiciones ante el aumento de precio del petróleo, que baja las utilidades de las empresas y lleva a un estancamiento con inflación. Para aprovechar el alza de precios del crudo, México comienza a petrolizar su economía en virtud de la crisis de energía, pero las medidas tomadas por Occidente desplo- 
marán los precios y el breve auge de abundancia concluirá con la catástrofe financiera de 1982.

Día 17 de septiembre, Monterrey: el rico empresario Eugenio Garza Sada, fundador de exitosas empresas y del Instituto Tecnológico de Monterrey, es asesinado por miembros de la Liga 23 de septiembre en un frustrado secuestro. A partir de este lamentable suceso, empresarios destacados iniciarán una campańa para denunciar que "nunca como ahora se ha visto la empresa privada tan amenazada, ni se ha puesto en duda la razón de ser de la misma". Pugnarán porque "el sector privado 'venda' una imagen adecuada de sus actividades"; "es un error vivir de espaldas a la política" (Carmona, 2014: internet).

Así, nacerá el Consejo Coordinador Empresarial (CCE) en 1975 (Carmona, 2014: internet) a instancias del embajador norteamericano Robert Mc Bride, con el propósito de "agrupar, representar y defender los intereses del sector privado mexicano y para defender la libertad de emprender" (Carmona, 2014: internet). Hoy, a todas horas, el Consejo de Comunicación del CCE, principal sostén mexicano del neoliberalismo, nos obliga constantemente a escuchar la Voz de las Empresas y las de los jóvenes emprendedores Pepe y Toño, a través de los medios de comunicación masiva.

Vayamos por partes: ¿qué es el neoliberalismo? ¿Por qué resulta opuesto a las ideas de lo que se llamó Revolución Mexicana, expresadas en la Constitución de 1917? Según los economistas de la UNAM Carlos Tello y Jorge Ibarra:

La característica fundamental del pensamiento Neoliberal consiste en asumir al individuo, indiferenciado, abstracto, como el referente principal de la explicación de los fenómenos sociales... asume al individuo como el arquitecto de su propio destino, sin ponderar el contexto social en el que se desenvuelve. El individuo, en libertad, actúa en función de sus propios intereses, que es capaz de visualizar con toda claridad. Esta es la esencia de la naturale- 
za humana. Y la mejor manera de que la persecución del interés propio se pueda potenciar y convertir en beneficio mutuo para todos los individuos a la vez, es el intercambio que se realiza en el mercado en un contexto de libre competencia. [...] Cualquier esquema de acción que sustituya, coarte o aletargue el desempeño individual independiente es considerado como una fuente de erosión de la libertad y el progreso.

El neoliberalismo constituye una versión extrema, y posiblemente sesgada, del pensamiento liberal tradicional... no concibe a un Estado pasivo, que se abstenga simplemente de intervenir en la esfera económica, sino a uno que actué todo el tiempo para salvaguardar y extender la presencia del mercado, garantizar su buen funcionamiento y enfrentar las cortapisas a la libre competencia (2013: 33- 38).

Para contrastar estas ideas neoliberales con las expresadas en la Constitución, acudamos a un texto de Vicente Lombardo Toledano, ideólogo y político destacado del siglo pasado:

lo importante en el Congreso Constituyente de Querétaro es que murió históricamente el pensamiento liberal. ¿Por qué murió históricamente el pensamiento liberal mexicano? Porque la filosofía liberal se basa en el individuo, en la persona física como base y objeto de las instituciones sociales; en cambio, este liberalismo renovado, progresista, muy avanzado de la Asamblea de Querétaro invierte los términos. En 1857 se dijo: primero la persona, después la familia, después la nación. En Querétaro, en 1917, se dijo: primero la nación, después el individuo.

Liquidado el pensamiento liberal que hacía del Estado una fuerza vigilante sólo de las transacciones entre los particulares, la nueva Carta Magna le da al Estado una importancia interesantísima, muy grande, como factor directo de la economía nacional. Muere también el pensamiento liberal porque muere el concepto romano de la propiedad. El derecho de usar, disponer y abusar de la propiedad sin límite ninguno; el famoso derecho romano, que 
hacía de la propiedad privada la base de todas las instituciones, desaparece en Querétaro, y la propiedad es concebida ya como un fin social y no como un privilegio privado. Además, muere el liberalismo, porque la reforma agraria representa un paso de enorme trascendencia no sólo en la concepción filosófica del derecho, sino también en la concepción económica y en el pensamiento relativo a las relaciones sociales. La tierra, las aguas, las riquezas naturales del territorio pertenecen a la nación, que tiene el dominio y siempre lo ha tenido sobre todas ellas.[...] el Congreso Constituyente de Querétaro, al lado de las garantías individuales, crea otras: las garantías sociales. Ya no es el concepto individualista el que priva; ahora hay que agregar a los derechos individuales los derechos colectivos contenidos en los artículos 27 y 123 (Apud Carmona, 2014: internet).

¿Qué mayor oposición entre estas dos expresiones del pensamiento político? Quizás la respuesta apresurada de Reyes Heroles a los sucesos de Chile la motivó también su conciencia de la extraordinaria vulnerabilidad que ha tenido México frente al exterior. Es decir, vislumbró una poderosa fuerza que llegaría a México, capaz de derribar ideologías e instituciones.

En su primer siglo de existencia, México pudo sobrevivir al imperialismo norteamericano y al colonialismo europeo a costa de "ceder" más de la mitad de su territorio y sufrir un lustro de intervención extranjera; de vivir muy brevemente los prolegómenos de la democracia juarista, para luego degenerar en una larga dictadura impuesta para la explotación voraz de sus más valiosos recursos por poderes extranjeros; ejerció tímida y esporádicamente su débil soberanía, y excluyó del bienestar a la gran mayoría de su población. El porfirismo fue la expresión de una tendencia global de la que México no estuvo a salvo. En Perú, Argentina, Colombia, Venezuela, Chile y Ecuador se establecieron dictaduras similares, en donde las elites nacionales, como los "científicos" mexicanos, servían como agentes de intereses extranjeros. 
En su segundo siglo de vida, tras una década de violencia revolucionaria, y en la coyuntura propicia de la Primera Guerra Mundial, México encontró el camino en un nacionalismo defensivo y en un Estado promotor de su desarrollo socio-económico y tutelar de las clases más desprotegidas. También, halló su identidad nacional en sus raíces populares e indígenas. ${ }^{1}$ Emprendió la marcha, resistiendo amenazas y presiones internacionales de los que se beneficiaron en su pasado, apretando el paso cuando la situación internacional distraía a las potencias en sus conflictos y guerras. La revolución triunfante culminó con la expropiación petrolera en 1938, que significó tanto la afirmación de la soberanía nacional y del Estado como la expresión de su nacionalismo.

En las décadas siguientes, la ruta mexicana hacia el progreso, vista por la derecha internacional como socializante, ya no fue tan cuestionada porque en las potencias capitalistas comenzó a estructurarse lo que se conocería como el Estado de Bienestar, que pretendía la protección social del individuo desde antes de nacer y de la cuna a la tumba. Las cuatro libertades esenciales del presidente Roosevelt de 1941 y la Alianza para el Progreso del presidente Kennedy de 1960 (Cfr. Carmona, 2014: internet) resultaron, para fortuna de la Revolución Mexicana, congruentes con el rumbo que México había tomado institucionalmente desde 1917. México y el mundo capitalista caminaron por la misma senda, aliados para vencer al nazifascismo.

En el prólogo al libro conmemorativo de los primeros 50 años del inicio de la Revolución, el presidente Adolfo López Mateos escribía:

Bajo la vigencia de los principios revolucionarios, concebimos al Estado como promotor de la justicia social. Por consiguiente, su

${ }^{1}$ Estos principios y políticas fueron una respuesta a los males del porfiriato y en conjunto se les identifico como "nacionalismo revolucionario". 
acción se orienta a favorecer a las clases populares y a procurar la elevación de sus niveles de vida mediante la mejor distribución de la riqueza, las normas tutelares del trabajo, la seguridad social y la enseñanza (Apud Carmona, 2014: internet).

México era una tierra de sueños y esperanzas para la mayoría de sus habitantes. Sus ideas revolucionarias impactaban al mundo. Su diplomacia impecable le merecía el liderazgo de sus países hermanos latinoamericanos. Su revolución social le daba identidad y lo hacía diferente a otras naciones. Hasta merecedores fuimos de una sede Olímpica. Así, México comenzó a obtener logros económicos y sociales, siempre insatisfactorios respecto a lo necesario, pero al fin logros. Eran tiempos del "desarrollo estabilizador", que mediante un Estado activo y una economía mixta combinaba crecimiento con inflación en lo que se llamó el "milagro mexicano".

Durante la guerra fría sobrevivimos virando a la derecha, aceptando términos injustos de intercambio comercial internacional por nuestras materias primas y esquivando presiones para subordinarnos a los bloques ideológicos capitalismo/comunismo en pugna. Pese a todo, México mantuvo un gobierno civil cuando Estados Unidos imponía dictaduras militares en América Latina e inició su industrialización y mejoró sus niveles de bienestar social, como no lo había hecho antes, como no lo ha hecho ahora. No obstante, el precio del progreso material y social fue una democracia sin contenido real, un autoritarismo periódicamente represivo, corrupción creciente y crisis económicas cada vez más profundas. Lo más grave fue no superar la estructura social que, como un fantasma, nos persigue desde la colonia.

A partir de las últimas tres décadas, tras la crisis que culminó con la nacionalización de la banca, la ideología dominante en México durante más de medio siglo dio un giro de 180 grados, contra el cual sólo se rebeló la fracción priísta que, tras el fraude electoral de 1988, formaría el Partido de la Revolución Democrática (PRD). 
Así llegamos a nuestro tiempo, donde todo se sujeta a la crítica destructiva, al repudio y finalmente a la sustitución por sus opuestos: desde la no reelección en los cargos de representación política, la promoción del Estado en la vida económica y social, la economía mixta, la incompatibilidad entre ser político y ser empresario, la austeridad republicana, la solidaridad, la expansión de los servicios sociales y la tutela de los derechos de los trabajadores; hasta el nacionalismo, el fomento de la identidad nacional, la protección a la industria mexicana y la prohibición de la inversión extranjera en áreas consideradas básicas. Hoy lo que antes era blanco es negro.

Olvidamos el informe del militar Félix María Calleja al virrey sobre los Estados Unidos, que "por su proximidad, intereses y relaciones deben ser siempre nuestros enemigos naturales y permanentes" (Carmona, 2014: internet) y, sin embargo, los hicimos nuestros socios.

La historia patria, a la que tanto acudían los políticos para hallar inspiración y legitimar sus acciones, se convirtió en un engaño oficial, algo vergonzoso, prescindible y necesariamente olvidable por ser obstáculo a la modernidad. ¿Por qué la historia patria? Porque la historia promovía valores, ideales, arquetipos y paradigmas, que resultaban contrarios al neoliberalismo.

Antes, los presidentes mexicanos se percibían a sí mismos como actores o herederos de una Revolución original y auténticamente mexicana, cuyos propósitos había que cumplir. Hoy, pretenden ser agentes de la modernidad y la globalización. Basta analizar el discurso político, desde Venustiano Carranza hasta José López Portillo en comparación con el expresado por los últimos presidentes, para darse cuenta que sufrimos una verdadera contrarrevolución de la que sólo podemos ser conscientes quienes nacimos antes de 1973.

¿En verdad vivimos tan equivocados durante siete décadas? El pasado no tuvo continuidad. La revolución mexicana parece que 
nunca existió. De las palabras Nación, Pueblo, Patria, Ciudadano, Justicia Social ni quien se acuerde. El pensamiento y el debate políticos actuales tienen más raíces en el siglo XIX que en el XX. Las políticas y prácticas gubernamentales vuelven a transitar por los viejos caminos probados del porfirismo, sin considerar que la Revolución se dio, justamente, contra esas políticas y esas prácticas. ¿La historia se repite helicoidalmente como propuso Abenjaldún?

En el ámbito internacional: ¿Cómo, en unas cuantas décadas, pasamos de la Alianza para el Progreso al Consenso de Washington? (Carmona, 2014: internet) ¿Del presidente Kennedy, que buscaba aliarse con México y América Latina, al presidente Obama que espía a sus socios y al mundo entero?

El cambio siempre ha sido objeto de la Filosofía de la Historia. Por eso, más que presentar la Memoria Política de México, que está a su completa disposición en la Internet, he aprovechado esta oportunidad para presentar algunas inquietudes y reflexiones. Para nosotros, filósofos e historiadores, el neoliberalismo debe ser objeto de reflexión porque no es una ideología más, está convirtiéndose en el pensamiento mundial único dominante. Por mi parte, creo que el culto al mercado empobrece la vida, la imaginación y las aspiraciones humanas. Me resisto a pensar que el arquetipo del individuo maximizador de medios para fines utilitarios egoístas sea la síntesis de la naturaleza humana y que de la suma de egoísmos individuales resulte el progreso social. Tampoco considero que todas las manifestaciones de la vida deban tener su principio y fin en el mercado ni que el neoliberalismo constituya el destino inexorable de la humanidad.

Desarrollado desde el poder del dinero por un grupo de políticos, empresarios y académicos, el neoliberalismo — señala David Harvey - propone todo un aparato conceptual atractivo "a nuestras instituciones e instintos, a nuestros valores y nuestros deseos y, también, a las posibilidades inherentes del mundo social que habi- 
tamos [...] ha sido exitoso porque encaja de tal forma en el sentido común, que se da por supuesto y no abierto al cuestionamiento" (2007: 11). Anclado en los ideales políticos de la dignidad humana y la libertad individual como valores centrales de la civilización, el neoliberalismo ha conformado toda una ideología, que según Manfred B. Steger y Ravi K. Roy ha sido codificada

por las élites del poder mundial, entre las que se encuentran directivos y ejecutivos de grandes multinacionales, grupos de presión empresarial, periodistas de prestigio... intelectuales que escriben para públicos amplios, gente del espectáculo, artistas, funcionarios estatales y políticos. En tanto que principales defensores del neoliberalismo, estos individuos saturan el discurso público con imágenes idealizadas de un mundo de libre mercado y consumista. Su habilidad para negociar con los medios de comunicación les permite vender a un público muy amplio su versión favorita del mercado global unificado, y proyectar una imagen positiva del mismo, en tanto que herramienta imprescindible para construir un mundo mejor (2010: 10-15).

Estas acciones coordinadas, que convierten el poder del dinero en poder persuasivo mediante propaganda, publicidad, relaciones públicas y cabildeos para influir en las mentes de las masas y de sus dirigentes, están unidas a la formación y promoción de políticos dedicados a defender los intereses empresariales, así como al establecimiento u orientación de instituciones educativas y de investigación económica, en las que los postulados de la economía neoliberal llegan a ser ciencia exacta, ajena a ideologías, equiparable a las ciencias duras, demostrable con complejos modelos matemáticos y aplicable a cualquier situación y país. Estos valores, técnicas y prácticas empresariales se han trasladado al gobierno, que es concebido ineficaz y corrupto por naturaleza. La administración pública moderna aspira a ser una réplica de las empresas de clase mundial y a 
convertir a los ciudadanos, a los que debe servir, en meros clientes. Además, dada la pretendida superioridad de la empresa comparada con la gestión pública, se instaura el government by contract, o gobierno por contrato, ${ }^{2}$ en el que todas las funciones públicas pueden ser objeto de concesión a las empresas particulares; como consecuencia se forman organizaciones público-privadas, supuestamente para sacar ventaja de ambos tipos de organismos, cuando en realidad sólo generan ganancias a las empresas privadas.

Todas estas acciones, concertadas del capitalismo a nivel global, hacen pensar a autores como Carlos Tello y Jorge Ibarra (2013) que está en marcha una verdadera revolución de los ricos, cuyo propósito es influir en las políticas gubernamentales y en la creación de un ambiente con los valores propicios a los intereses de las clases más altas dentro de cada país y a nivel mundial. Según Tello e Ibarra, las victorias de esta revolución se expresan en los mercados monopólicos, en las cuantiosas utilidades, en las exenciones e impuestos regresivos, en las condonaciones de adeudos fiscales, en los créditos blandos, en los frecuentes rescates financieros a diversas empresas a costa del erario, en los estratosféricos sueldos, en los dividendos y prestaciones de los ejecutivos públicos y privados y en los nuevos multimillonarios que registra la revista Forbes. ${ }^{3}$ Por otro lado, la derrota de los pobres está en el desmantelamiento del Estado de Bienestar, en los salarios de hambre, en la fragilidad del empleo, en el florecimiento del outsourcing que nulifica derechos laborales, en el aumento de los impuestos al consumo como el

${ }^{2}$ El contratismo que prevalece propicia desde la simulación, el favoritismo y, desde luego, la corrupción. Hoy todo se considera objeto de negocio y lo mismo se privatizan las instituciones culturales que las policías y las cárceles.

${ }^{3}$ La organización internacional Oxfam denuncia [...] que las élites ricas se reparten el poder político para manipular las reglas del juego económico, socavando la democracia y creando un mundo en el que las 85 personas más acaudaladas acumulan tanta riqueza como la mitad de la población más pobre del planeta junta. 
IVA, en la inflación general que deteriora su poder adquisitivo, en tener como única opción de empleo la economía informal y, finalmente, en el desempleo y la miseria urbana generalizada.

Para explicar por qué ha sido posible este cambio profundo comparto algunas conjeturas: en el nivel internacional fue posible por el desequilibro de poder provocado por la desintegración de la Unión Soviética, que ha permitido al capitalismo mundial avanzar sin límite, riesgo, ni competencia significativa. En un nivel local, nuestra historia revela momentos hegemónicos similares: la conquista de México y de Latinoamérica cuando, con la legitimidad de una Bula papal y durante varios siglos, Espańa no tuvo contrincante que le disputara eficazmente la riqueza minera de estas tierras. El conquistador y el fraile erradicaron la civilización indígena y sobrepusieron la suya. Otro momento crucial fue el despojo de más de la mitad de nuestro territorio por los Estados Unidos, que tuvo lugar en una coyuntura mundial en la que a ninguna potencia europea le convenía ni ayudar a México ni disputarle el botín a los norteamericanos, quienes anexaron las tierras que quisieron.

Un caso similar sucedió durante la intervención francesa, cuando los estadounidenses, únicos interesados en preservar sus intereses en nuestro país y América Latina, no podían actuar por estar en plena guerra civil; no obstante, con la derrota de los sureńos, comenzó a declinar la acción impune de los franceses.

En el siglo XX, alarmado por el avance del comunismo que ya llegaba al Caribe, Kennedy tuvo que ofrecer alianzas a los pueblos latinoamericanos para que no miraran hacia el socialismo. En contraste, en el siglo XXI y sin la amenaza del comunismo, Obama no tiene por qué hacer ese tipo de concesiones: hace avanzar los intereses norteamericanos con ayuda de los organismos internacionales que supuestamente deben servir a todos los países que los integran. En consecuencia, a pesar de una aparente multipolaridad internacional, el poder militar-financiero de Estados Unidos es he- 
gemónico y determinante en las relaciones internacionales. Así, el neoliberalismo se ha abierto camino sin oponente alguno.

Existen otros factores mundiales que explican el cambio referido por ejemplo, el rápido desarrollo de la ciencia y tecnología, el cual ha dado una gran movilidad a los capitales, a las materias primas y a los productos manufacturados. Por conveniencia, el neoliberalismo es cada vez más la ideología de quienes tienen en sus manos la decisión de invertir y retirar capitales. Incluso los gobiernos pueden ser presionados con la una fuga de capitales si no cooperan en el afán de obtener altas utilidades a cualquier costo. Por otra parte, surgieron las comunicaciones en tiempo real. A partir de los satélites y después con la Internet, surge la posibilidad de llegar instantáneamente a millones de personas y, por lo tanto, de poder influir sus mentes. Si a esto se agrega el desarrollo de las neurociencias, de la tecnología de la persuasión, de la mercadotecnia y de la investigación de la opinión pública, es claro que se ha multiplicado el potencial de influencia sobre las mentes, de manera abierta o subliminal; es decir, por abajo de los límites normales de la percepción (Cfr. Martínez, 2011: internet). Así, el neoliberalismo ha podido tanto propagar eficazmente su culto por el individualismo, el mercado y la empresa, como desprestigiar todo intervencionismo y toda corriente de pensamiento económico distinto, o dicho en sus propios términos: todo populismo y keynesianismo. El resultado es que hoy, existen millones de personas que sólo se informan por medio de la televisión y la radio, es decir, ven el mundo sólo desde la perspectiva de los valores empresariales.

Otro factor más de carácter mundial es el fracaso de las democracias representativas en casi todos los países. La ilusión de la democracia se desvanece cuando el dinero genera influencia y poder político, cabe mencionar que desde el poder político se regenera este dinero en un ciclo degradante para la voluntad ciudadana. Por si esto fuera poco, las tendencias oligárquicas de las organizacio- 
nes políticas, empresariales y civiles, de los sindicatos, de las burocracias y en general de los gobiernos, desplazan los objetivos de servir a sus miembros a preservar sólo los intereses de quienes las manejan. Así, se abre la puerta a los acuerdos cupulares, a la manipulación, al cabildeo y a la corrupción. La gente común, el pueblo (como se decía antes) no tiene quien la represente, de modo que la democracia definida por Lincoln, el gobierno del pueblo por el pueblo y para el pueblo, es una ficción. En estas condiciones, entre más oligárquicos son los gobiernos son también más sensibles a la influencia, a la manipulación y a la captura por intereses ajenos, es decir, a ceder ante el neoliberalismo dando la espalda a sus pueblos, desechando su historia y su identidad nacional.

Los factores de carácter mundial que hasta ahora se han mencionado propiciaron el neoliberalismo global, pero impactaron de manera distinta a los países conforme a sus rasgos y situación interna. La tendencia general ha sido que, en los países con instituciones más débiles y sociedades más pobres y desiguales, el neoliberalismo ha tenido mayores consecuencias negativas para los pueblos.

En México, el neoliberalismo llegó en plena decadencia del régimen que surgió de la Revolución. Las élites gobernantes no fueron capaces de emprender las reformas necesarias para salvar el incipiente Estado de Bienestar, entre las que se encontraban: una reforma fiscal que gravara más a los sectores de altos ingresos, de modo que evitara la crisis de financiamiento de los servicios sociales, y una reforma política democrática, que fortaleciera la legitimidad del Estado y su poder popular frente a los crecientes grupos de interés nacionales y extranjeros, que además obligara a la rendición de cuentas y creara el control ciudadano anticorrupción. Con el auge del libre comercio internacional se debió levantar paulatinamente (no de un sopetón como se hizo) el proteccionismo económico que había fracasado en promover el crecimiento de empresas eficientes y competitivas. Tampoco se intentó una polí- 
tica económica que no dependiera del petróleo como la principal fuente de ingreso para el financiamiento del gasto gubernamental ni una política de población que regulara más eficazmente el crecimiento demográfico, para que no erosionara los avances en el desarrollo humano. Al contrario, los grupos que se beneficiaron de la política económica de la Revolución (como el de Monterrey o Televisa) o que surgieron de la corrupción gubernamental impune (como el del ex-presidente Alemán o del político Hank González) resistieron todo intento de cambio que los afectara y se vigorizaron con el neoliberalismo que fue impuesto, por poderes extranjeros, a los últimos gobiernos del PRI en el siglo XX, tras la frustrada nacionalización de la banca. Fue entonces cuando el crecimiento económico prácticamente se detuvo junto con la movilidad política y social. ${ }^{4} \mathrm{La}$ élite política comenzó a perpetuar los cargos y a formarse en instituciones privadas y norteamericanas y ya no en la UNAM. Al liberarse el régimen surgieron los asesinatos políticos, la rebelión zapatista y, finalmente, mostró su presencia sangrienta el crimen organizado.

No obstante, el partido en el poder decidió, por sí mismo o por influencia exterior, pactar una transición hacia la democracia con los grupos de izquierda y de extrema derecha. Así, en las elecciones de 1997, la izquierda ganó la capital y, en el 2000, tuvo que reconocer la victoria obtenida en las urnas por la derecha y entregó la presidencia al candidato que había ofrecido "El cambio que a ti te conviene". Parecía que volvían los tiempos de sueños y esperanzas. Transitaríamos por fin a la democracia, pero no fue así. El cambio prometido no llegó. En lugar de sustituir las bases políticas del antiguo régimen y avanzar hacia la democracia, el gobierno "del cambio" las aprovechó y, junto con los grupos empresariales neoli-

${ }^{4}$ Con la reelección, la llamada clase política perderá movilidad, ya que el "efecto del titular" le permitirá fácilmente permanecer en sus puestos durante varios años (Vid. Martínez/Salcedo, 2006: 60). 
beralistas más conservadores y más poderosos, todos temerosos del poder ciudadano, cortaron de tajo el puente hacia la democracia.

Escribe Simon Johnson: "En todo tiempo y lugar, las personas poderosas siempre procuran hacerse del control total del gobierno menoscabando el progreso social en favor de su propia codicia" (Apud Acemoglu/ Robinson, 2012). Al desmantelarse el Estado fuerte que había surgido de la Revolución y al salir el PRI del gobierno después de setenta ańos, en lo que parecía una transición democrática, los grupos de poder político, económico, social, militar, religioso y, lógicamente, el crimen organizado, que también ya era un poder, disputaron los vacíos de autoridad dejados por el Estado. Escribe Edgardo Buscaglia:

En cualquier transición política desde un sistema autoritario siempre es mucho más fácil reconfigurar instituciones del antiguo régimen que construir nuevas con base en consensos políticos y sociales democráticos. Es por ello que la mayoría de las transiciones políticas genera enormes vacíos de poder institucional de Estado, que luego aprovechan y ocupan actores no estatales, que pueden presentarse como televisoras oligopólicas o empresas criminales trasnacionales, los cuales empiezan a transformarse en autoridades de facto remplazando así al Estado mismo. En este tipo de contextos, las empresas criminales compiten salvajemente por ocupar estos vacíos de Estado mediante mayores niveles de violencia y de corrupción de las autoridades políticas, las que venden sus curules y resoluciones administrativas o judiciales al mejor postor. A través de esta encarnizada competencia para ocupar vacíos de Estado, los actores no estatales buscan consolidar su dominio sobre mercados de bienes y servicio: legales e ilegales (2013: 160).

¿Por qué se ha podido dar un giro político tan radical en relativa paz? ¿Por qué, en contraste, si en todos los países existe el crimen organizado no hay tanta violencia y muertes como en el nuestro? Comparto una conjetura más como respuesta: por la indignan- 
te desigualdad, lacerante pobreza y vergonzosa ignorancia, que hacen de millones de mexicanos carne de manipulación política, mediática, mercadológica; campo propicio para corromper y ser corrompido. Esto degenera a la sociedad en una especie de mercado cautivo de todos los poderes legales e ilegales, una nueva "encomienda" en constante disputa pacífica o violenta. En esta lucha, el neoliberalismo cuenta con un extraordinario poder de persuasión y control de las masas. Los medios masivos, particularmente la televisión, han hecho posible que la mayoría dominada se vea a sí misma con los ojos de sus dominadores. Escribió Hitler: “¿A quién debe dirigirse la propaganda? ¿A los intelectuales o a la masa menos instruida? ¡Ella debe dirigirse siempre y únicamente a la masa!” (Martínez/ Salcedo, 2006: internet).

La democracia, aun la electoral, se convierte en una quimera frente a una estructura social de desigualdad e ignorancia, que permite el clientelismo y la compra del voto, y al monopolio de los medios informativos, que hace posible la manipulación de grandes masas de electores en favor de las oligarquías más poderosas. Además, durante el tiempo que las élites empresariales han promovido el neoliberalismo en México, se ha duplicado la población, lo cual significa que los ciudadanos menores de cuarenta ańos ya no conocieron la ideología de la Revolución sino sólo la del neoliberalismo. Maquiavelo señaló: el vulgo se deja cautivar "por las apariencias y el resultado de las cosas, y en el mundo no hay más que vulgo" (2011: 60). ¿Será como decían los nazis, que "los pueblos entienden poco y olvidan mucho"?

La razón en cuanto al porqué sufrimos tantos hechos de sangre, creo que se desprende de la codicia institucionalizada que hoy vivimos, llevada y vendida a una masa marginada y fascinada por la riqueza, fuente inagotable de sicarios, que no encuentra otra salida más que la de matar antes de ser muerto y, en el ínterin, gozar un poco de lo que piensan es vivir mejor. 
En menos de una década México será bicentenario y hoy estamos cada vez más alejados de hacer realidad los Sentimientos de la Nación de Morelos.

¿Por qué México sigue pobre tras doscientos años de vida independiente? Este es un tema de filosofía de la historia, o debería de serlo. ¿Qué distingue a un país rico de uno pobre? Para Acemoglu y Robinson, la posibilidad de ser un país rico no está en la latitud geográfica ni en los recursos naturales, tampoco en la cultura ni en saber manejar la economía eficazmente. La diferencia se da en la política: es pobre cuando una reducida élite es capaz de organizar a la sociedad en beneficio propio a costa de la mayoría de su población; es rico cuando el poder está repartido y ningún grupo es capaz por sí sólo de imponer leyes y reglas para beneficio propio y, por ende, para sometimiento de los demás (Acemoglu/ Robinson, 2012).

En México, la Independencia, la Reforma y la Revolución fueron intentos frustrados por abrir las oportunidades de progreso para todos. Sin embargo, hoy, para conservar privilegios y monopolios, en medio del estancamiento económico y la violencia sangrienta, se buscan salidas como la reforma energética que, a juicio de Lorenzo Meyer, puede ser un caballo de Troya definitivo en el destino de México (2013). Woodrow Wilson escribió: "Un país es poseído y dominado por el capital que en él se haya invertido" (Apud Quinn, 2010: 90). Diría José Joaquín Fernández de Lizardi, hace casi doscientos años: "¿Y en qué piensan los mexicanos para hacer estas ventas escandalosas a los extranjeros? ¿ No advierten que a ese paso, dentro de pocos años, ya no serán sino unos huérfanos en su país, pues no tendrán ni un palmo de tierra que sembrar ni un rincón en que vivir? ¿No conocen que los ingleses no conquistan con plomo sino con oro?" (Apud Carmona, 2014: internet).

Me pregunto: ¿Comprenderán algún día nuestras clases dominantes que el principal obstáculo a nuestro desarrollo son los 
privilegios y monopolios que se resisten a abandonar? ¿Cuántas lágrimas, cuánto dolor, cuántas vidas más costará a los mexicanos, especialmente a los indígenas, la entrega al extranjero de nuestros recursos naturales?

\section{Bibliografía}

Acemoglu, Daron y James Robinson, 2012, Por qué fracasan los países Los orígenes del poder, la prosperidad y la pobreza, Bogotá, Deusto.

Buscaglia, Edgardo, 2013, Vacíos de poder en México. El camino de México hacia la seguridad humana, México, Debate.

Carmona Dávila, Doralicia, 2014, Memoria politica de México, disponible en: http://www.memoriapoliticademexico.org

Harvey, David, 2007, La breve historia del neoliberalismo, Madrid, Akal.

Manfred B., Steger y Ravi K. Roy, 2010, Neoliberalism. A Very Short Introduction, Nueva York, Oxford University Press.

Maquiavelo, Nicolás, 2011, Obra selecta, Madrid, Gredos.

Martínez Silva, Mario y Roberto Salcedo Aquino, 2006, Manual de campaña, disponible en: http://manual.inep.org/I/I-III.html ,2006, Manual de campaña. Diccionario Electoral, México, Instituto Nacional de Estudios Políticos.

Quinn, Adam, 2010, US Foreign Policy in Context: National Ideology from the Founders to the Bush Doctrine, Londres, Routledge.

Tello, Carlos y Jorge Ibarra, 2013, La Revolución de los Ricos, México, UNAM.

(Artículo recibido el 7 de enero de 2014; aceptado el 25 de febrero de 2014) 
